\title{
Responsabilidade civil das escolas quanto a violência física e moral: a construção do saber na era conectada
}

\author{
Civil liability of schools as to physical and moral violence: the construction of knowledge in the \\ connected age
}

Raquel Rosan Christino Gitahy

Doutora em Educação pela Universidade Paulista Júlio de Mesquita Filho, docente da Universidade do Oeste Paulista e da Universidade Estadual do Mato Grosso do Sul raquel gitahy.rg@gmail.com

Luis Henrique Ramos Alves

Discente do curso de Bacharelado em Direito da Universidade do Oeste Paulista.Estagiário do Ministério Público do Estado de São Paulo (MPSP). Membro do Grupo de Estudos e Pesquisas em Educação, Currículo e Tecnologias, da Universidade do Oeste Paulista (UNOESTE). Membro do Grupo de Pesquisa Acesso a Justiça, Inovação e Sustentabilidade, da Universidade do Oeste Paulista

(UNOESTE). luishenrique981@hotmail.com

Fernanda Gabriela Sampaio Souza

Discente do Ensino Médio da ETEC Professor Doutor Antônio Eufrásio de Toledo. Bolsista do CNPQ, vinculada a Universidade do Oeste Paulista. PIBIC-EM. fer2014gabih@gmail.com

Resumo: Este artigo teve como objetivo analisar o uso do ambiente virtual para auxiliar na construção do saber da sociedade sobre a responsabilidade civil das escolas no que se refere à violência física e moral. A fim de atingir tal objetivo, a pesquisa teve uma abordagem qualitativa, utilizando o contexto do ambiente virtual de aprendizagem do site "Saber o direito", criado para interações entre a sociedade e especialistas no tema responsabilidade civil das escolas. Para a coleta de dados foram utilizados os registros documentados de tais interações. A análise dos dados fez-se a partir dos saberes construídos e a legislação vigente, tendo como norte as duvidas e os relatos de experiências envolvendo o tema. Esta pesquisa proporcionou, a partir de relatos postados em ambiente virtual, compreender problemas envolvendo a responsabilidade civil no caso de violência escolar e quais são as soluções jurídicas para tais situações.

Palavras chaves: Responsabilidade civil. Escola. Violência.

Abstract: This article aimed to analyze the use of the virtual environment to assist in the construction of society 's knowledge about the civil responsibility of schools regarding physical and moral violence. In order to reach this objective, the research had a qualitative approach, using the context of the virtual learning environment of the site "Knowing the right", created for interactions between society and specialists in the subject of responsibility of schools. For data collection, documented records of such interactions were used. The analysis of the data was made based on the knowledge built and the legislation in force, having as the background doubts and reports of experiences involving the theme. This research provided, from reports posted in a virtual environment, to 
understand problems involving civil liability in the case of school violence and what are the legal solutions to such situations.

Keywords: Civil liability. School. Violence.

\section{Introdução e revisão de literatura}

Estando a escola atual inserida em uma sociedade conectada, pode-se usar as informações constantes no meio digital para se discutir mais amplamente o tema responsabilidade civil das escolas quanto a violência, conscientizando os profissionais envolvidos na escola, os pais e toda a sociedade. A importância do assunto já foi salientada pelo doutrinador e professor Carlos Roberto Gonçalves:

\footnotetext{
Grande é a importância da responsabilidade civil, nos tempos atuais, por se dirigir à restauração de um equilíbrio moral e patrimonial desfeito e à redistribuição da riqueza de conformidade com os ditames da justiça, tutelando a pertinência de um bem, com todas as suas utilidades, presentes e futuras, a um sujeito determinado. (GONÇALVES, 2016, p.22).
}

A Responsabilidade Civil possui como objetivo não deixar que a pessoa vítima de danos materiais ou morais fique sem indenização.

O Código Civil Brasileiro nos traz em seu art. 927, que "Aquele que, por ato ilícito, causar dano a outrem, fica obrigado a repará-lo", ainda neste dispositivo o parágrafo único vem nos dizer que "Haverá obrigação de reparar o dano, independentemente de culpa, nos casos especificados em lei, ou quando a atividade normalmente desenvolvida pelo autor do dano implicar, por sua natureza, risco para os direitos de outrem”, além disso nos traz o art.186 que, "Aquele que, por ação ou omissão voluntária, negligência ou imprudência, violar direito e causar dano a outrem, ainda que exclusivamente moral, comete ato ilícito".

Diante do exposto nos artigos é possível observar que o Código traz uma proteção à vítima a qual recai a conduta ilícita. E levando em consideração essa proteção e até mesmo o que diz o Parágrafo Único do art.927, será que é possível pensar em uma responsabilidade civil da escola quando o ato ilícito da violência ocorre no interior da mesma? A sociedade conhece a responsabilidade civil da escola? Como podemos usar a informação constante no mundo virtual para divulgar o tema?

A partir destas questões, fomos incitados a estudar a responsabilidade civil das escolas no que se refere a violência na era do virtual.

Atualmente a responsabilidade civil é regida pelo Código Civil Brasileiro de 2002, que adota duas responsabilidades para a configuração da indenização, que é a Responsabilidade Civil Subjetiva e a Responsabilidade Civil Objetiva, ambas possuem algumas particularidades e 
diferenças entre si, sendo possível termos casos em que se nasce um dever de indenizar sem a presença do requisito culpa ou dolo.

A Responsabilidade Civil Subjetiva funda-se na ideia de Culpa, "a culpa é tratada como um pressuposto para a configuração da responsabilidade civil subjetiva", como afirma Carlos Roberto Gonçalves (2016, p.48). É possível vislumbrar essa responsabilidade a partir da leitura dos arts.186 e 927 do Código Civil.

O dever ressarcitório pela prática de atos ilícitos decorre da culpa, ou seja, da reprovabilidade ou censurabilidade da conduta do agente. O comportamento do agente será reprovado ou censurado quando, ante as circunstâncias concretas do caso, se entende que ele poderia ou deveria ter agido de modo diferente. Portanto, o ato ilícito qualifica-se pela culpa." (DINIZ, 2016, p.57).

$\mathrm{Na}$ Responsabilidade Civil Objetiva, a lei impõe a algumas pessoas, diante de alguns fatos, tenham o dever de reparar o dano independentemente de culpa, há aqui a presunção de que todo dano de alguma forma deve ser indenizado. Consta do art. 927 Júnico do Código Civil que "Haverá obrigação de reparar o dano, independentemente de culpa, nos casos especificados em lei, ou quando a atividade normalmente desenvolvida pelo autor do dano implicar, por sua natureza, risco para os direitos de outrem.”

Por meio da análise da Responsabilidade Subjetiva e Objetiva, surge-se o seguinte questionamento: a responsabilidade civil da Escola quanto à violência é objetiva ou subjetiva?

O ambiente escolar é um lugar onde o aluno desenvolve um aprendizado, uma atividade intelectual; dentro deste ambiente o aluno possui contato com outras pessoas, que podem ser alunos, professores, diretores e funcionários em geral. A partir dessa convivência pode-se surgir problemas e até mesmo atos ilícitos decorrentes de ação ou omissão, culpa ou dolo; fazendo nascer assim uma Responsabilidade Civil. Mas quem responderá por essa responsabilidade civil? E será que todos a conhecem?

De acordo com o que se extrai do Código Civil Brasileiro em seu art. 932, IV, são responsáveis pela reparação civil dos educandos os estabelecimentos com fins de educação, a escola possui sob a sua direção pessoas para serem educadas e escolas deverão responder de forma Objetiva (Responsabilidade Civil Objetiva) e até mesmo solidariamente, bastando apenas comprovar o nexo causal, ação ou omissão e o dano.

No entender de conceituados autores, como Alvino Lima, Serpa Lopes e outros, em relação aos mestres e educadores preside a mesma ideia que influi na responsabilidade dos pais, com esta diferença de que a responsabilidade dos educadores é vinculada a um dever de vigilância pura e simplesmente, enquanto aos pais incumbe não só a vigilância como a educação (GONÇALVES, 2016, p.136).

A escola deve se responsabilizar tanto pelos danos sofridos por terceiros, quanto pelos danos sofridos pelos próprios alunos. Segundo Nicolau e Nicolau (2006, p. 240-241): 
No convívio escolar o aluno deve ser protegido para que não sofra qualquer dano, seja de ordem moral ou material e esta proteção tem que ser a preocupação maior da própria instituição que o abriga. [...].O dano a ser indenizado não se restringe apenas ao dano material e estético, pois as instituições de ensino não são apenas responsáveis pela incolumidade física de seus alunos, mas, também, por danos morais e à imagem de cada um deles que ali estão para se tomarem melhores, mais sábios, respeitados e dignificados e qualquer lesão praticada no ambiente escolar deve ser evitada pela escola sob pena de se responsabilizar por ela. Isso já ocorre no cotidiano vivenciado por estudantes, notadamente menores ou do ensino fundamental, provando que as indenizações por dano moral mudam a relação colégio (professor) e alunos, impedindo que traumas infantis ou de adolescência se repitam, evitando-se prejuízo.

Podemos citar como exemplo a expansão da prática do Bullying que hoje é muito comum entre crianças e adolescentes e a conduta omissiva da escola quando presente um caso deste, dentro do interior da mesma, fazendo com que nasça um dano moral.

\begin{abstract}
Assim, quando o aluno se encontra em regime de externato, a responsabilidade é restrita ao período em que o educando está sob a vigilância do educador (Serpa Lopes, ob.cit., n.284), compreendendo o que ocorre no interior do colégio, ou durante a estada do aluno no estabelecimento, inclusive no recreio (Pontes de Miranda), ou em um veículo de transporte fornecido pelo educandário. O mais que ocorra fora do alcance ou da vigilância do estabelecimento estará sujeito ao princípio geral de incidência de culpa". (GONÇALVES, 2016, p.137).
\end{abstract}

A Responsabilidade Civil pode ser uma responsabilidade vindo contra escola particular ou pública em face do município ou estado. Dentro da escola particular a reparação será feita pela própria escola. No âmbito da Escola Pública a reparação será feita pelo Município ou pelo Estado, devendo ser apurado se a escola era municipal ou estadual. A Constituição Federal, em seu art. $37, \$ 6^{\circ}$ traz que "as pessoas jurídicas de direito público e as de direito privado prestadoras de serviços públicos responderão pelos danos que seus agentes, nessa qualidade, causarem a terceiros, assegurado o direito de regresso contra o responsável nos casos de dolo ou culpa".

A Responsabilidade Civil das Escolas é um tema que vem crescendo dentro dos Tribunais Brasileiros e já temos vários julgados nesse sentido. Como por exemplo, houve um caso no Tribunal de Justiça do Rio Grande do Sul em que foi pedido por meio de apelação civil, a responsabilidade civil do município, pelo estabelecimento de ensino ter faltado com o dever de vigilância, ao deixar que ocorresse a fuga de um menor de idade. (AC 70044152023 RS). Ainda neste mesmo Tribunal houve um caso em que um aluno perdeu $90 \%$ da visão do olho esquerdo por agressão de outro aluno. (AC 70057453433 RS).

Como divulgar a responsabilidade civil para a sociedade, professores e gestores? Será que o ambiente virtual pode auxiliar na construção do saber social sobre a responsabilidade civil das escolas no caso de danos vindos de atos de violência (física e moral)? 
A tecnologia de informação e comunicação é uma ferramenta que pode ser utilizada para fins educacionais. De acordo com Gabriel (2013), antigamente, o principal meio de se educar era a fala, com o passar do tempo a sociedade passou a adotar os livros, que trouxe a leitura silenciosa e individualizada e com a popularização da internet no fim do séc.XX, começa a nascer as trocas de experiências e discussões por meios virtuais.

O Aprendizado do tema Responsabilidade Civil é algo de suma importância na sociedade que atualmente é considerada digital e conectada, sendo possível pensar em uma educação digital para se construir o saber social sobre responsabilidade civil das escolas no que se refere a violência.

\footnotetext{
Hoje, a necessidade de atualização constante requer que todos estudem o tempo todo, independentemente da idade que tenham. A educação não para mais, em idade nenhuma. Dessa forma, a educação de adultos, e não mais apenas de jovens, passa a ser uma vertente importante na Era Digital (GABRIEL,2013, p.100)
}

A Responsabilidade Civil das Escolas quanto a violência física ou moral é um tema que deve ser de conhecimento de todos, e por meio do ambiente virtual é possível a reflexão sobre o mesmo. Escolhemos o ambiente "Saber Direito", como contexto da presente pesquisa.

\section{Objetivos}

\subsection{Objetivo Geral}

Analisar o uso do ambiente virtual para auxiliar na construção do saber da sociedade sobre a responsabilidade civil das escolas no que se refere a violência física e moral ocorridas no ambiente escolar.

\subsection{Objetivos Específicos}

Investigar as dúvidas postadas em sites como "Saber o Direito" a respeito da responsabilidade civil das escolas no caso de violência

Comparar as soluções discutidas em sites sobre a responsabilidade civil das escolas com a jurisprudência sobre o assunto

\section{Metodologia}

Para responder às nossas questões de pesquisa, optamos pela abordagem qualitativa. A abordagem de investigação qualitativa "exige que o mundo seja examinado com a ideia de que nada é trivial, que tudo tem potencial para constituir uma pista que nos permita estabelecer uma compreensão mais esclarecida do nosso objeto de estudo" (BODGAN E BIKLEN, 1994, p.49). 
O contexto da pesquisa foi o ambiente virtual de aprendizagem do site "Saber o direito", criado para interações entre a sociedade e especialistas no tema responsabilidade civil das escolas, tendo objetivo educacional, por meio de textos de fácil entendimento, aproximar o Direito dos cidadãos. O endereço do ambiente é http://direitodetodos.com.br/

A pesquisa utilizou dos documentos registrados das interações realizadas no site Direito de todos. Tais interações envolvem membros da sociedade e especialistas no tema Responsabilidade civil das escolas e violência.

Salientamos que esta pesquisa não necessitou da tramitação no comitê de ética pois todas as interações que serão objeto de análise são de acesso público.

\section{Análise dos resultados}

A análise dos dados foi realizada a partir dos saberes construídos e legislação vigente, tendo como norte as duvidas e os relatos de experiências envolvendo o tema responsabilidade civil das escolas no caso de violência. A tabela 1 evidencia os fatos ocorridos na escola, relatados no site Saber o Direito.

Tabela 1 -Fatos ocorridos na escola relatados pela sociedade no site "Saber o Direito"

\begin{tabular}{|l|c|}
\hline \multicolumn{1}{|c|}{ Fatos ocorridos na escola } & $\begin{array}{c}\text { Porcentagem de fatos } \\
\text { mais frequentes }\end{array}$ \\
\hline Bullying & $3,4 \%$ \\
\hline Danos morais & $3,4 \%$ \\
\hline Falta de segurança/vigilancia & $20,6 \%$ \\
\hline Furto & $6,8 \%$ \\
\hline Lesão corporal & $62 \%$ \\
\hline Perda de material & $3,4 \%$ \\
\hline
\end{tabular}

Fonte: construído pelos autores a partir dos dados do site "Saber o Direito"

Diante da tabela acima, conseguimos verificar que as Lesões Corporais aparecem com um maior número de acontecimentos o que causa uma grande preocupação uma vez que se trata de algo que envolve um grande risco à saúde, com isso o Código Civil Brasileiro (BRASIL 2002) e a doutrina se posiciona no sentido de que as lesões corporais ou outra ofensa à saúde, devem ser indenizadas e essa indenização levará em consideração as despesas com o tratamento da lesão 
e dos lucros cessantes até o fim da convalescença, além disso terá que indenizar qualquer outro tipo de prejuízo que o ofendido possa ter vindo a sofrer.

Abaixo vemos excertos dos responsáveis relatando casos de lesão corporal na escola

\section{Cristiane}

$\underline{06 / 25 / 2016 \text { às } 01: 56}$

Minha filha todo dia reclama que o colega tá batendo nela e agora ela tá vindo pra casa com roxo no corpo porque diz que o colega bateu nela hoje chegou com o rosto vermelho que o colega atirou uma pedra nela a escola e responsável por cuidar dela no recreio? Como devo proceder? Fonte:http://direitodetodos.com.br/escola-e-responsavel-pelo-aluno-e-sua-integridade-fisica/

\section{Lucas silvsy}

$\underline{11 / 16 / 2016 \text { às } 02: 09}$

Fui agredido fisicamente dentro da sala de aula por uma aluna, eu simplesmente fui agredido com um tapa na cara e todos a volta riram de mim. Procurei a direção da escola e não fizeram nada. Posso fazer algo em relação a isso ou simplesmente vou ter que aceitar e ficar quieto?

Fonte:http://direitodetodos.com.br/escola-e-responsavel-pelo-aluno-e-sua-integridade-fisica/

Entretanto devemos analisar ainda se a lesão corporal deixou algum defeito pelo qual o ofendido não possa exercer o seu ofício ou profissão, ou se a lesão lhe diminuiu a capacidade de trabalho, se isto ocorrer teremos a indenização, além das despesas com o tratamento e lucros cessantes até o fim da convalescença, incluirá pensão correspondente à importância do trabalho para que se inabilitou, ou da depreciação que ele sofreu. (Art. 949 e Art.950 CC).

Levando-se ainda em consideração as Lesões Corporais a Jurisprudência já se posicionou no sentido de responsabilidade da escola pelas lesões ocorridas em seu estabelecimento de ensino:

ACÓRDÃO EMENTA. CIVIL E PROCESSUAL CIVIL. ADMINISTRATIVO. APELAÇÃO CÍVEL. RESPONSABILIDADE CIVIL ESTATAL. UNICÍPIO DE BOA ESPERANÇA. ESCOLA MUNICIPAL. AGRESSÃO DE CRIANÇA POR OUTRO ALUNO. RESPONSABILIDADE OBJETIVA OMISSIVA. DESCUMPRIMENTO DO DEVER DE VIGILÂNCIA. DANOS MORAL E MATERIAIS. DIREITO AO RESSARCIMENTO.1. A responsabilidade civil estatal, relativamente a qualquer das unidades federativas, é objetiva, seja em condutas comissivas ou omissivas. Precedentes do STF, STF e TJES. 2. O município deve ser responsabilizado pelos danos morais e materiais suportados por criança agredida no pátio da unidade de ensino por outro aluno, caracterizado o descumprimento do dever legal do ente público de garantir a segurança e incolumidade física das crianças sob sua custódia. Precedentes do STF e TJES.

(TJ-ES - APL: 00003527320168080009, Relator: SAMUEL MEIRA BRASIL JUNIOR, Data do Julgamento: 17/04/2018, TERCEIRA CÂMARA CÍVEL, Data de Publicação: 27/04/2018). 
O segundo maior número de ocorrências relatado no site "Saber o Direito", é a Falta de Segurança e Vigilância dentro do recinto escolar. As escolas possuem um dever de vigilância durante o período em que as crianças estão sobre a sua tutela, com isso quando não há uma vigilância eficaz nasce a responsabilidade civil para a escola. Abaixo um excerto sobre a falta de vigilância

\section{Felipe Piacenti \\ $\underline{02 / 10 / 2017 \text { às } 11: 26}$}

Daniel,

Entendo que você pode fazer notificações ou reclamações junto à diretoria regional ou secretaria municipal de ensino informando que determinada escola não está oferecendo a segurança adequada aos alunos.

Abraço

Fonte:http://direitodetodos.com.br/escola-e-responsavel-pelo-aluno-e-sua-integridade-fisica/

Falta de Segurança ou Vigilância podem acontecer de inúmeras formas, desde a entrada de pessoas estranhas ao recinto escolar colocando em risco a segurança e integridade física dos alunos, até mesmo a fuga destes, principalmente com relação às crianças, diante disso o Código Civil (BRASIL 2002) preceitua que também serão responsáveis pela reparação civil os donos de hotéis, hospedarias, casas ou estabelecimentos onde se albergue por dinheiro, mesmo para fins de educação, pelos seus hóspedes, moradores e educandos; (art. 932, IV), além disso o Código ainda traz em seu artigo 933 que (BRASIL 2002) “As pessoas indicadas nos incisos I a V do artigo antecedente, ainda que não haja culpa de sua parte, responderão pelos atos praticados pelos terceiros ali referidos.", trazendo assim a responsabilidade civil objetiva, que haverá uma reparação independente de culpa, nesse sentido o Tribunal de Justiça do Rio Grande do Sul já decidiu que:

APELAÇÃO CÍVEL. RESPONSABILIDADE CIVIL. MUNICÍPIO.
ESTABELECIMENTO DE ENSINO. CRECHE MUNICIPAL. FUGA DE
MENOR ABSOLUTAMENTE INCAPAZ. FALTA DO DEVER DE
VIGILÂNCIA. DANO MORAL. DEVER DE REPARAÇÃO. Hipótese dos autos
em que há evidente falta do dever de vigilância do Município, na medida em que a
criança de tenra idade (01 ano e 10 meses) deixada em creche municipal por sua
genitora, fugiu do estabelecimento de ensino sem que fosse percebida sua falta por
qualquer dos professores ou responsáveis, e acabou sendo encontrada em cima de um
pontilhão sobre um arroio próximo da creche. (Tribunal de Justiça do Rio Grande do
Sul TJ-RS - Apelação Cível : AC 70044152023 RS - Inteiro Teor).

O terceiro maior número de acontecimentos foi relacionado a Furtos ocorridos dentro da escola. A doutrina não chega a tratar sobre o assunto, entretanto a jurisprudência já se pronunciou no sentido de que a escola tem que indenizar os furtos ocorridos dentro do seu 
recinto se esta foi negligente com o dever de vigilância a ela imposta, diante disso a jurisprudência já decidiu que:

CIVIL E PROCESSUAL CIVIL. CERCEAMENTO DE DEFESA. NÃO CARACTERIZADO. RESPONSABILIDADE CIVIL. ESCOLA PARTICULAR. FURTO. CÂMERA DIGITAL DE ALUNA MENOR. DEVER DE INDENIZAR. SENTENÇA MANTIDA.

1. NÃO HÁ QUE SE FALAR EM CERCEAMENTO DE DEFESA QUANDO GARANTIDO ÀS PARTES O CONTRADITÓRIO E A AMPLA DEFESA. ADEMAIS, NÃO SE VISLUMBRA A RELEVÂNCIA DA IDADE DA FILHA DA APELADA PARA O DESATE DA QUESTÃO, MORMENTE QUANDO ESTA SE CINGE EM AFERIR A RESPONSABILIDADE DE ESTABELECIMENTO DE ENSINO EM INDENIZAR DANOS MATERIAIS OCORRIDOS EM SEU RECINTO.

2. O FATO DA APELANTE DISPOR NO CONTRATO DE PRESTAÇÃO DE SERVIÇOS, FIRMADO COM A APELADA, QUE SE EXIME DA RESPONSABILIDADE POR PERDAS OU EXTRAVIOS QUE OCORRAM NAS DEPENDENCIAS DA ESCOLA, BEM COMO PELO RESPECTIVO RESSARCIMENTO, NÃO A DESOBRIGA DO DEVER DE VIGILÂNCIA, POR CONSEGUINTE, DA POSSIBILIDADE DE VIR A SER RESPONSABILIZADA, SE DESCUROU DESSE DEVER.

3. TENDO A ESCOLA SE DESCURADO DE SEU DEVER DE VIGILÂNCIA SOBRE OS PERTENCES DA ALUNA QUANDO OCORREU A SUBTRAÇÃO, RESTA CARACTERIZADA A CULPA IN VIGILANDO, E, PORTANTO, O DEVER DE REPARAR O DANO. 4. É PACÍFICO QUE SENDO REMUNERADO PELOS SERVIÇOS EDUCACIONAIS QUE PRESTA, OBRIGA-SE A ESCOLA PELA INTEGRIDADE DOS ALUNOS E DE SEUS PERTENCES. 5. SOBRE O TEMA ESTA EGRÉGIA TURMA JÁ DECIDIU: "(...) SE O ESTABELECIMENTO, NEGLIGENCIANDO SEU DEVER DE VIGILÂNCIA, VEM A PERMITIR QUE A MOCHILA DA ALUNA SEJA VIOLADA DURANTE ESSE INTERREGNO, E SEU APARELHO CELULAR FURTADO, NÃO TEM COMO SE EXIMIR DA RESPONSABILIDADE PELA REPARAÇÃO DO DANO. DECISÃO: NEGAR PROVIMENTO. UNÂNIME." (20040110152894ACJ, RELATOR JESUÍNO APARECIDO RISSATO, PRIMEIRA TURMA RECURSAL DOS JUIZADOS ESPECIAIS CÍVEIS E CRIMINAIS DO D.F., JULGADO EM 18/04/2006, DJ 24/05/2006 P. 122) - NEGRITEI. 6.A UNILATERALIDADE DA REFERIDA CLÁUSULA CONTRATUAL, PREVENDO A EXCLUSÃO DA RESPONSABILIDADE PELOS PERTENCES DOS ALUNOS, NÃO DEVE SURTIR EFEITO, POIS FERE DIREITO BÁSICO DO CONSUMIDOR À EFETIVA REPARAÇÃO DOS DANOS SOFRIDOS (ART. $6^{\circ}$, INCISO VI, DA LEI 8.078/90). 7. NOS TERMOS DO ARTIGO 55 DA LEI DOS JUIZADOS ESPECIAIS (LEI No 9.099/95), CONDENO O APELANTE AO PAGAMENTO DAS CUSTAS PROCESSUAIS E HONORÁRIOS ADVOCATÍCIOS QUE FIXO EM 10\% SOBRE O VALOR DA CONDENAÇÃO. 8. RECURSO CONHECIDO E IMPROVIDO, LEGITIMANDO A LAVRATURA DO ACÓRDÃO NOS MOLDES AUTORIZADOS PELO ARTIGO 46 DA LEI N ${ }^{\circ}$ 9.099/95. UNÂNIME. (TJ-DF - ACJ: 20060610032497 DF, Relator: NILSONI DE FREITAS, Data de Julgamento: 21/11/2006, Primeira Turma Recursal dos Juizados Especiais Cíveis e Criminais do D.F., Data da Publicação: DJU 07/02/2007 Pág.: 114).

Nas análises de questionamentos dentro do site, encontramos pedido de danos morais em face da Escola. Tal possibilidade é totalmente cabível quando estamos tratando sobre Responsabilidade Civil das Escolas, uma vez que um fato ocorrido dentro do recinto pode vir acarretar de acordo com a Doutrina, danos não somente na órbita patrimonial mas também danos que ofende o ofendido como pessoa, danos que podem vir a abalar e provocar uma 
situação angustiante por parte do ofendido, diante disso nos dizeres de Carlos Roberto Gonçalves (2016 , p. 387 e 388 ):

Dano moral é o que atinge o ofendido como pessoa, não lesando seu patrimônio. É lesão de bem que integra os direitos da personalidade, como a honra, a dignidade, a intimidade, a imagem, o bom nome etc., como se infere nos arts. $1^{\circ}$, III, e $5^{\circ}, \mathrm{V}$ e X, da Constituição federal, e que acarreta ao lesado dor, sofrimento, tristeza, vexame e humilhação.

O Site "Saber Direito" traz algumas perguntas dos pais relacionados a prática do Bullying dentro do espaço escolar. Abaixo um excerto relatando tal fato:

\section{Sophia dos Santos}

04/01/2016 às 00:04

Estou enfrentando problemas na minha escola por causa que tem um menino que está com depressao e muita agressividade e diz que quer se vingar do bullying que ele recebeu. Todos estão preocupados mas a escola não faz absolutamente nada! Eu entendo que ele está doente mas ele fica sempre nos ameaçando e todos têm medo que ele faça alguma coisa. O que os alunos podem fazer?

Fonte:http:/ / direitodetodos.com.br/escola-e-responsavel-pelo-aluno-e-sua-integridade-fisica/

Atualmente dentro das escolas e até mesmo na sociedade encontramos a prática do Bullying, segundo Ana Beatriz Barbosa Silva (2010, p.21)

[...] o bullying corresponde a um conjunto de atitudes de violência física e/ou psicológica, de caráter intencional e repetitivo, praticado por um bully (agressor) contra uma ou mais vítimas que se encontram impossibilitadas de se defender [...].

De acordo com a conceituação deste termo é possível verificar que a prática do bullying configura um ato ilícito e caso o estabelecimento de ensino venha de alguma forma se omitir em tomar providências relativas a isso, negando a existência do problema por exemplo, ou até transferindo essa responsabilidade para a própria família da criança, ou até mesmo não realizando nenhuma das ações anteriores, é certo que a escola será responsável civilmente uma vez que a escola tem a obrigação de manter o aluno seguro, resguardando a sua integridade tanto física como psíquica, que decorrem do dever de vigilância que os pais transferem a escola mesmo que de forma temporária, além disso a própria legislação vigente traz em seu artigo 186 do Código Civil (BRASIL 2002) que "Aquele que, por ação ou omissão voluntária, negligência ou imprudência, violar direito e causar dano a outrem, ainda que exclusivamente moral, comete ato ilícito." Analisando-se a legislação vigente é possível ver que há a prática de um ato ilícito diante a omissão da escola, e ainda conjugando este artigo com o artigo 927 do Código Civil veremos que (BRASIL 2002) “Art. 927. Aquele que, por ato ilícito, causar dano a outrem, fica obrigado a 
repará-lo. Parágrafo único. Haverá obrigação de reparar o dano, independentemente de culpa, nos casos especificados em lei, ou quando a atividade normalmente desenvolvida pelo autor do dano implicar, por sua natureza, risco para os direitos de outrem." Ainda nesse sentido a jurisprudência dos tribunais vem entendendo que:

\begin{abstract}
APELAÇÕES CÍVEIS. RESPONSABILIDADE CIVIL. AÇÃO DE INDENIZAÇÃO POR DANOS MORAIS. BULLYING NO AMBIENTE ESCOLAR. LESÕES. DANO MORAL CARACTERIZADO. QUANTUM INDENIZATÓRIO.1. O autor logrou comprovar os fatos articulados na exordial, o postulante foi agredido no ambiente escolar, em duas oportunidades, o que resultou em uma lesão no olho e um braço quebrado, em evidente desrespeito a dignidade pessoal deste.2.É passível de ressarcimento o dano moral causado no caso em exame, decorrente de o autor ter sido lesionado, sem que houvesse injustamente provocado, tal medida abusiva resulta na violação ao dever de respeitar a gama de direitos inerentes a personalidade de cada ser humano, tais como a integridade física, a imagem, o nome e a reputação da parte ofendida.3. As referidas ofensas dão conta de um fenômeno moderno denominado de bullying, no qual adolescente se dedica a maltratar determinado colega, desqualificando-o em redes sociais perante os demais e incitando estes a prosseguirem com a agressão, conduta ilícita que deve ser reprimida também na esfera civil com a devida reparação, pois é notório que este tipo de ato vem a causar danos psíquicos na parte ofendida, levando, em alguns casos, ao suicídio.4. No que tange à prova do dano moral, por se tratar de lesão imaterial, desnecessária a demonstração do prejuízo, na medida em que possui natureza compensatória, minimizando de forma indireta as conseqüências da conduta da parte ré, decorrendo aquele do próprio fato. Conduta ilícita do demandado que faz presumir os prejuízos alegados pela parte autora, é o denominado dano moral puro.5. O valor a ser arbitrado a título de indenização por dano imaterial deve levar em conta o princípio da proporcionalidade, bem como as condições da ofendida, a capacidade econômica do ofensor, além da reprovabilidade da conduta ilícita praticada. Por fim, há que se ter presente que o ressarcimento do dano não se transforme em ganho desmesurado, importando em enriquecimento ilícito. Quantum mantido. Negado provimento aos recursos. (Apelação Cível No 70059883637, Quinta Câmara Cível, Tribunal de Justiça do RS, Relator: Jorge Luiz Lopes do Canto, Julgado em 24/09/2014).
\end{abstract}

Interessante que dentro do julgado dessa jurisprudência encontramos a fala de um dos relatores ao momento de expressar seu voto que é de suma importância para a concretização da ideia de dever de indenização da escola em caso de Bullying, o Des. Jorge Luiz Lopes do Canto (RELATOR) diz que:

Caracterizou-se a falha do serviço prestado pelo requerido na sua omissão em não valorar os efeitos danosos das "brincadeiras" que alega, consistentes em agressões leves entre os alunos. Ao não minorar o problema das "brincadeiras" entre alunos, a escola acaba por permitir, negligentemente, que o ato ilícito seja perpetrado em suas dependências, caracterizado não só pela agressão física, como também pela violação dos direitos inerentes à própria dignidade do aluno. (Apelação Cível No 70059883637 , Quinta Câmara Cível, Tribunal de Justiça do RS, Relator: Jorge Luiz Lopes do Canto, Julgado em 24/09/2014).

Diante do voto e dos dizeres do relator é possível solidificar a teoria de que a escola é responsável pela dignidade física e psíquica da criança enquanto está sob sua vigilância e dentro do recinto de ensino, além disso devemos considerar que a Dignidade da Pessoa Humana é algo de suma importância para a concretização dos direitos do homem e a escola como um local de 
ensino e aprendizagem deve zelar pela proteção a essa Dignidade que está prevista na Constituição Federal.

\section{Considerações finais}

A fim de finalizarmos o presente artigo, voltamos ao objetivo inicial, a saber: analisar o uso do ambiente virtual para auxiliar na construção do saber da sociedade sobre a responsabilidade civil das escolas no que se refere a violência física e moral ocorridas no ambiente escolar. Percebemos, pela pesquisa realizada, que existem situações de violência como lesão corporal, bullying, furto, dentre outras, que podem gerar a responsabilidade civil da escola.

Tal responsabilidade é prevista no artigo 932 do Código civil, pois o mesmo afirma que são também responsáveis pela reparação civil: "IV - os donos de hotéis, hospedarias, casas ou estabelecimentos onde se albergue por dinheiro, mesmo para fins de educação, pelos seus hóspedes, moradores e educandos".

O presente artigo evidenciou a importância de tal responsabilidade ser veiculada para a população e os profissionais da educação, sendo que se mostrou um importante meio as postagens no meio virtual.

A partir de uma maior conscientização da responsabilidade das escolas em relação à violência ocorrida, mais numerosos serão os processos visando à reparação do dano. A luta pela justiça e o fim da violência escolar continua!

\section{Referências}

BODGDAN, Roberto C.; BIKLEN, Sari Knopp. Investigação qualitativa em educação. Tradução Maria João Alvarez, Sara Bahia dos Santos e Telmo Mourinho Baptista. Porto: Porto Editora, 1994

BRASIL. Código Civil. Lei no 10.406, de 10 de janeiro de 2002. Disponível em http://www.planalto.gov.br/ccivil_03/leis/2002/110406.htm. Acesso em: 07 abr. 2018

BRASIL. Constituição (1988). Constituição da República Federativa do Brasil. Brasília: Senado Federal, 1988.

DINIZ, MARIA HELENA. Curso de Direito Civil Brasileiro, volume 7: Responsabilidade Civil - 30. ed. - São Paulo: Saraiva, 2016.

DISTRITO FEDERAL. Tribunal de Justiça do Distrito Federal. Apelação Cível no Juizado Especial. Apelação Cível no Juizado Especial n: 20060610032497. Apelante: Instituto Rio Branco de Ensino LTDA. Apelado: Eloina Helena Domingos. Relatora: Nilsoni de Freitas Custódio. Distrito Federal, 21 de Novembro de 2006. Disponível em: < https://tj- 
df.jusbrasil.com.br/jurisprudencia/2746217/apelacao-civel-no-juizado-especial-acj20060610032497-df/inteiro-teor-101083057?ref=juris-tabs>. Acesso em 25/03/2019.

ESPIRITO SANTO. Tribunal de Justiça do Espirito Santo. Apelação Cível. Apelação Cível n: 00003527320168080009. Apelante Thalita Souza Pacheco. Apelado: Município de Boa Esperança. Relator: Samuel Meira Brasil Junior. Espirito Santo, 17 de Abril de 2018. Disponível em: < https://tj-es.jusbrasil.com.br/jurisprudencia/574173260/apelacao-apl3527320168080009/inteiro-teor-574173263? ref=juris-tabs>. Acesso em: 25/03/2018.

GABRIEL, MARTHA. Educar, a Revolução Digital na Educação - 1. ed. - São Paulo: Saraiva, 2013

GONÇALVES, CARLOS ROBERTO. Direito Civil Brasileiro, volume 4: Responsabilidade Civil 11. ed. - São Paulo: Saraiva, 2016.

NICOLAU JUNIOR, M.; NICOLAU, C. C. M. B. Responsabilidade civil dos estabelecimentos de ensino: a eticidade constitucional. In: SLAIBI FILHO, N.;

COUTO, S. (Coord.). Responsabilidade civil : estudos e depoimentos no centenário do nascimento de José de Aguiar Dias (1906-2006). Rio de Janeiro: Forense, 2006

RIO GRANDE DO SUL. Tribunal de Justiça do Rio Grande do Sul. Apelação Cível. Apelação Cível n: 70044152023. Apelante Município de Santo Ângelo. Apelado Elisiane Machado Nunes. Relator: Tasso Caubi Soares Delabary. Santo Ângelo, 24 de Agosto de 2011. Disponível em: $<$ https://tj-rs.jusbrasil.com.br/jurisprudencia/20382010/apelacao-civel-ac-70044152023rs/inteiro-teor-20382011?ref=juris-tabs>. Acesso em: 28 mar.2018.

RIO GRANDE DO SUL. Tribunal de Justiça do Rio Grande do Sul. Apelação Cível. Apelação Cível n: 70057453433. Apelante Estado do Rio Grande do Sul. Apelado Adriele Boeira Camargo. Relator: Marcelo Cezar Muller. Rio Grande do Sul, 19 de Dezembro de 2013. Disponível em: <https://tj-rs.jusbrasil.com.br/jurisprudencia/113540332/apelacao-civel-ac-70057453433rs/inteiro-teor-113540342?.ref=juris-tabs > . Acesso em: 28 mar.2018.

RIO GRANDE DO SUL. Tribunal de Justiça do Rio Grande do Sul. Apelação Cível. Apelação Cível n: 70059883637. Apelantes Instituto Maria Imaculada - Medianeira e Leandro Lima de Souza. Relator: Jorge Luiz Lopes do Canto. Rio Grande do Sul, 24 de Setembro de 2014. Disponível em: < https://tj-rs.jusbrasil.com.br/jurisprudencia/142660826/apelacao-civel-ac70059883637-rs/inteiro-teor-142660836? ref=juris-tabs>. Acesso em: 25/03/2019.

RIO GRANDE DO SUL. Tribunal de Justiça do Rio Grande do Sul. Apelação Cível. Apelação Cível n: 70044152023. Apelante: Municipio de Santo Angelo. Apelado: Elisiane Machado Nunes. Relator: Tasso Caubi Soares Delabary. Rio Grande do Sul, 24 de Agosto de 2011. Disponível em: < https://tj-rs.jusbrasil.com.br/jurisprudencia/20382010/apelacao-civel-ac-70044152023rs/inteiro-teor-20382011>. Acesso em 25/03/2019. 
Recebido em: 10 abr. 2019 / Aprovado em: 25 jun. 2019

\section{Cite como}

GITAHY, Raquel Rosan Christino; ALVES, Luis Henrique Ramos; SOUZA, Fernanda Gabriela Sampaio. Responsabilidade civil das escolas quanto a violência física e moral: a construção do saber na era conectada. Dialogia, São Paulo, n. 32, p. 38-51, maio/ago. 2019. Disponível em: https://doi.org/10.5585/Dialogia.n32.13551. 